BANCA D'ITALIA

E U R O S I S T E M A

Questioni di Economia e Finanza

(Occasional Papers)

Measuring the aggregate effects of simplifying firm creation in ltaly

by Guzmán González-Torres 

13 BANCA D'ITALIA

E U ROS IS T E MA

\section{Questioni di Economia e Finanza}

(Occasional papers)

Measuring the aggregate effects of simplifying firm creation in Italy

by Guzmán González-Torres

Number 365 - November 2016 
The series Occasional Papers presents studies and documents on issues pertaining to the institutional tasks of the Bank of Italy and the Eurosystem. The Occasional Papers appear alongside the Working Papers series which are specifically aimed at providing original contributions to economic research.

The Occasional Papers include studies conducted within the Bank of Italy, sometimes in cooperation with the Eurosystem or other institutions. The views expressed in the studies are those of the authors and do not involve the responsibility of the institutions to which they belong.

The series is available online at www.bancaditalia.it.

ISSN $1972-6627$ (print)

ISSN 1972-6643 (online)

Printed by the Printing and Publishing Division of the Bank of Italy 


\title{
MEASURING THE AGGREGATE EFFECTS OF SIMPLIFYING FIRM CREATION IN ITALY
}

\author{
Guzmán González-Torres*
}

\begin{abstract}
A series of reforms passed in Italy in 2010 reduced the expected duration of registration and startup procedures for new businesses. Previous research found that procedural simplifications of this nature have a positive impact on the selection of firm entry in the short run and consequently on their productivity. These studies, based on natural policy experiments and lacking precise estimates for the duration of the startup process in Italy, are not designed to predict both the long-term effects and the aggregate implications of such reforms. Using a general equilibrium framework with heterogeneous firms and households, and micro-level data for Italian households, I provide an estimate for average startup times in Italy and find that further reforms of a similar nature could produce a significant increase in aggregate firm productivity and output, which is qualitatively in line with previous findings.
\end{abstract}

JEL Classification: E22, E23, E65, K23.

Keywords: firm size distribution, entrepreneurial selection, entry costs, aggregate productivity.

\section{Contents}

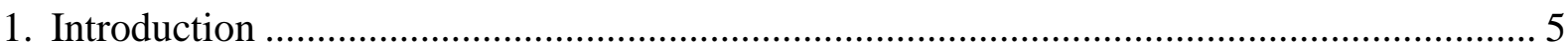

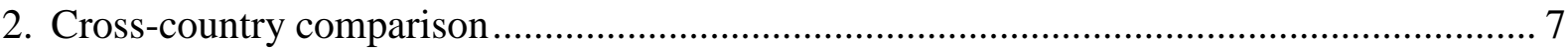

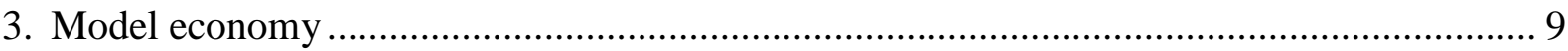

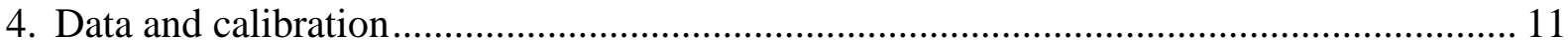

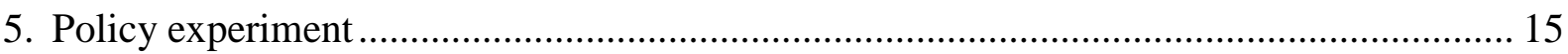

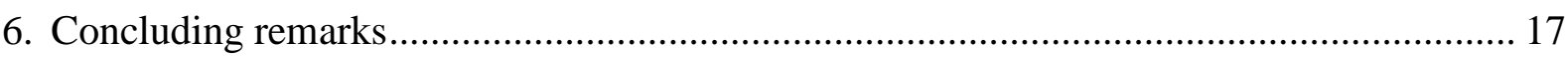

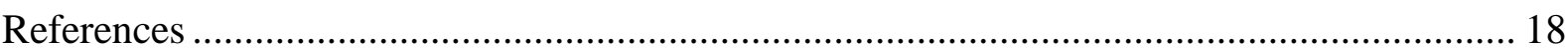

* Bank of Italy, Directorate General for Economics, Statistics and Research, Law and Economics Division. mailto:gonzalez-torres.guzman@esterni.bancaditalia.it 



\section{Introduction $^{1}$}

Some of the greatest barriers to the creation of businesses, and thus to the generation of competition, have traditionally originated from the various bureaucratic requirements encountered by those creating a business or entering a certain market for the first time, and those setting up additional establishments. These bureaucratic entry requirements are generally divided into two stages: creating a legal entity with the purpose of carrying out an economic activity - henceforth simply described as "registering a business" - and thereafter obtaining all the necessary permits to start performing the said activity - hereafter referred to as the "startup process". A growing literature ${ }^{2}$ has set out to measure these burdens across different countries, as well as to understand how they affect different aspects of the economy, such as aggregate output and productivity, firm and entrepreneurial selection, or income and wealth inequality. This body of work gradually triggered an increasing interest across different institutions - the most prominent of which led to the creation of the annually published World Bank Doing Business Report (www.doingbusiness.org) - and a subsequent set of policy responses across different countries.

Italian policymakers have taken part in these efforts in recent years through various reforms, of which 2010 was an especially active year. While the registration stage was divided into various steps before April 2010, the creation of the Comunicazione Unica, literally the "Single Notice", provided entrepreneurs with the possibility of registering their businesses in one step by filing a single document with the competent authority, who would then coordinate with the relevant agencies to record the creation of the new business in the corresponding registers. A later intervention, described and investigated by Amici et al. (2015), shortened expected startup process times by enhancing the efficiency of One-stop shops (OSSs henceforth). OSSs were created in 1998 and, similarly to the Comunicazione Unica, gave entrepreneurs the opportunity to process the startup of their previously registered businesses with a single agency.

Amici et al. (2015) find not only an increase in firm entry following this reform, but also a positive effect on firm selection: after reducing the time necessary to register a firm, entrants had a higher survival rate. These results are in line with other similar works: Seira, Kaplan, and Piedra (2007) and Bruhn (2011) take advantage of the SARE reform in Mexico, which is similar but preceded the Italian OSS reform. The number of procedures, therefore the time it took to register a firm, was reduced for a variety of industries on a local level. Seira et al. (2007) find that firm entry increased with the lower registration times. Simultaneously, the average entrant size increased after the reform. Although this could be due to improved entry selection, an alternative explanation might be that a greater number of already existing businesses suddenly found formalizing profitable. However Bruhn (2011), exploiting the same policy reform, finds that most of the newly registering entrepreneurs previously were wage earners, as opposed to informal business owners, thereby providing evidence against the latter hypothesis.

\footnotetext{
${ }^{1}$ I thank Silvia Giacomelli, Giuliana Palumbo, Giacomo Rodano, and Paolo Sestito for their detailed and insightful feedback, as well as Marco Tonello for his invaluable help. Any remaining errors are attributable to the author solely.

${ }^{2}$ Djankov (2009) provides an excellent overview of the literature up to that point.
} 
Some of these results, in particular those concerning an improved firm selection, contrast with earlier cross-country analyses such as those of Barseghyan (2008), Barseghyan and DiCecio (2010), and especially Klapper, Laeven, and Rajan (2006), which predict an influx of smaller firms after a reduction in startup costs. On a theoretical level, Gonzalez-Torres (2015) links the observed outcomes to the fact that the latter set of papers considers a reduction in the fixed fees owed for registration, as opposed to the former works which investigate the reduction in the time spent on such procedures. While a purely monetary fee deters individuals with lower productivity levels from entering entrepreneurship, ${ }^{3}$ high costs in terms of time have a negative selection effect on entrepreneurs: increasing the time needed to comply with bureaucratic registration and startup procedures poses a fixed cost of entry that increases with an agent's ability to generate income, i.e. the opportunity cost of devoting time to bureaucratic tasks increases. Higher quality entrepreneurial projects are less likely to be pursued, compared with lower quality projects. The average quality of projects pursued by entrepreneurs is thus negatively affected by increased registration and startup procedures.

This previous literature suggests that expanding these types of reforms might have sizable aggregate effects. In this paper I illustrate how a reduction in registration times compares to shortening startup processing times in terms of affecting the productivity, size, and output of Italian firms. In order to do so, I calibrate an appropriately adapted version of the model proposed in Gonzalez-Torres (2015) to reproduce related moments of the Italian economy. I use micro data on household finances and private firm management from the Italian Survey on Household Income and Wealth (SHIW) to pin down entrepreneurs' financial constraints in the model - which potentially have an important impact on aggregate productivity by preventing entrepreneurs from operating at their optimal scale - as well as their share of business projects' income. The SHIW also helps me determine the size of publicly traded businesses in relation to the set of privately held firms ${ }^{4}$ - both self-employed, as well as incorporated establishments - and the productivity distribution of the latter. I use data on the universe of Italian firms from the European Statistical Office (Eurostat) to reflect firm dynamics in the model economy.

In order to quantify all the entry costs faced by entrepreneurs, I proceed in two steps. I use the World Bank's Doing Business Report-which provides an approximation of how the firm registration process works and how long it takes - to pinpoint the reduction of expected registration times after the introduction of the Comunicazione Unica from 10 to 6 days. It is much harder to summarize and quantify all the startup costs faced by a firm as opposed to the registration process. Works like De Novellis et al. (2015), who survey a sample of Italian firms on their experiences during their startup processes, shed some light on the matter, but the length and costs of startup processes are not systematically or precisely measured. This is mainly due

\footnotetext{
${ }^{3}$ Hopenhayn (1992), Melitz (2003), and Clementi and Palazzo (2013) develop similar examples of industry dynamics models that illustrate this point.

${ }^{4}$ Publicly traded firms are arguably neither subject to the same financial constraints nor to startup costs as privately held firms are. An immediate example is that firms with greater resources can more easily afford to appoint the tasks required to overcome some hurdles to specialized agents, thus reducing the time they demand and freeing the project managers from these tasks.
} 
to the complex nature of the startup process, which may also vary significantly across industries, or to geography. Consequently, there is no previous measure of the impact the OSS reform had on startup times that I can use in my framework. I use my model to estimate the initial length of the startup process, of about 4 months, faced by the segment of Italian firms I study.

I conduct the following quantitative experiment within a general equilibrium model of occupational choice with ex-ante identical agents facing idiosyncratic managerial productivity shocks: I reduce the time needed to comply with the registration process from 10 to 6 days, as reported by the Doing Business Report after the introduction of the Comunicazione Unica. I then compare the effects of that policy intervention to reducing startup processing times by $40 \%$, an analogous reduction to that of registration times, given the aforementioned lack of estimates of the effects of the OSS reform on startup times. I measure the steady state deviations of several aggregate variables - such as output, productivity, entrepreneurial entry selection, or income and wealth inequality - with respect to the baseline calibration of the model.

As expected, the qualitative results of the policy experiment coincide with those in previous studies, including Gonzalez-Torres (2015), i.e. entrepreneurial selection improves with the drop in processing times, as does firm productivity and production. Quantitatively, the exercise shows that the aggregate effects of a reduction in startup times, as targeted by the OSS reform, could be significant, and orders of magnitude larger than the benefits of further reducing registration times - on which remarkable progress has already been made, as measured by Doing Business to have shrunk from 23 days in 2004 to 6 days after the introduction of the Comunicazione Unica in 2010. These estimates have significant implications, as efforts in the design of future policies should be shifted from registration costs, traditionally taken as a proxy for all entry costs, to all the procedures in the startup process for firms.

Section 2 presents the empirical regularities I set out to study, using mostly European and US data. Section 3 describes the model I use to conduct the policy experiment introduced above. Section 4 discusses the scope and limitations of my exercise, presents the data I use, and describes the calibration process of the model outlined in the preceding section. Section 5 presents the outcomes of the policy experiment I conduct. Section 6 concludes.

\section{Cross-Country Comparison}

In this section I present some descriptive data illustrating the relative magnitude of the registration and startup hurdles faced by entrepreneurs in Italy compared with other advanced economies, and why they might matter in aggregate terms.

Registration and startup costs vary significantly across European countries: nevertheless, they have historically been higher in comparison with other OECD countries. This is illustrated in Table 1, which summarizes the average time it takes to register a business across a selection of OECD countries, and the values in terms of income per capita of all the fixed fees due during the process. Even though the methodology is far from being a complete measurement ${ }^{5}$ of all the

\footnotetext{
${ }^{5}$ See Djankov et al. (2002) for the original work that led to the creation of the Doing Business report.
} 
hurdles entrepreneurs face when registering their businesses ${ }^{6}$ it is widely used in the literature. One key assumption when gathering this data, which I will incorporate into the model below, is that the time listed represents a period in which entrepreneurs are solely devoted to bureaucratic tasks, therefore not producing any goods or services.

Table 1: Time and monetary bureaucratic costs of starting a business

\begin{tabular}{cccc} 
Country & Procedures & Total days & $\begin{array}{c}\text { Monetary Cost } \\
\text { (\% Income p.c.) }\end{array}$ \\
\hline \hline Australia & 3 & 2.5 & 0.8 \\
Canada & 2 & 5.5 & 0.4 \\
France & 5 & 6.5 & 0.9 \\
Germany & 9 & 17.5 & 4.7 \\
Italy & 6 & 10 & 17.9 \\
Japan & 8 & 22 & 7.5 \\
Netherlands & 6 & 8 & 5.6 \\
Spain & 10 & 61 & 15 \\
UK & 6 & 10.5 & 0.7 \\
US & 6 & 5 & 0.7 \\
\hline
\end{tabular}

Source: Doing Business report 2010

Although there has been an important reduction in red tape in recent years, the differences in entry hurdles persist. Simultaneously, the firm size distribution is significantly more skewed towards smaller establishments in European countries, which I illustrate for the Italian case, when compared to the US in Figure 2.1. Philippon and Véron (2008) document the decline in the proportion of European firms that make it into the FT Global 500, a list of the 500 firms with the largest market capitalization world-wide. Europe does not seem to be able to produce extraordinarily large, productive firms.

Gonzalez-Torres (2015) shows that, in the case of $\operatorname{Spain}^{7}$, the rate of entrepreneurship does not seem to differ significantly from that of the US. In contrast, the empirical evidence -including that above - suggests it seems to be the case that entrepreneurial selection differs between Europe and the US: there does not seem to be a deficit of entrepreneurs, rather, the ones who enter seem to be less productive than their American counterparts. The goal of the model is thus to highlight the microeconomic mechanisms through which the different types of entry costs - both monetary and time-related hurdles - can affect entrepreneurial and firm entry selection, and the resulting productivity and size distributions.

\footnotetext{
${ }^{6}$ On the one hand, it only takes into account a very initial and arguably small subset of all the requirements met by any entering firm. Additionally, it does not take into account various circumstances such as geographical or industry heterogeneity.

${ }^{7}$ The Italian case is very similar in this regard: the percentage of households owning and actively running a business adds up to $14.25 \%$ using the 2010 wave of SHIW, whereas for the Spanish and US cases this figure is $14.2 \%$ and $12.4 \%$ respectively, using equivalent data sources.
} 
Figure 2.1: Firm Size Distribution in Italy vs. the US

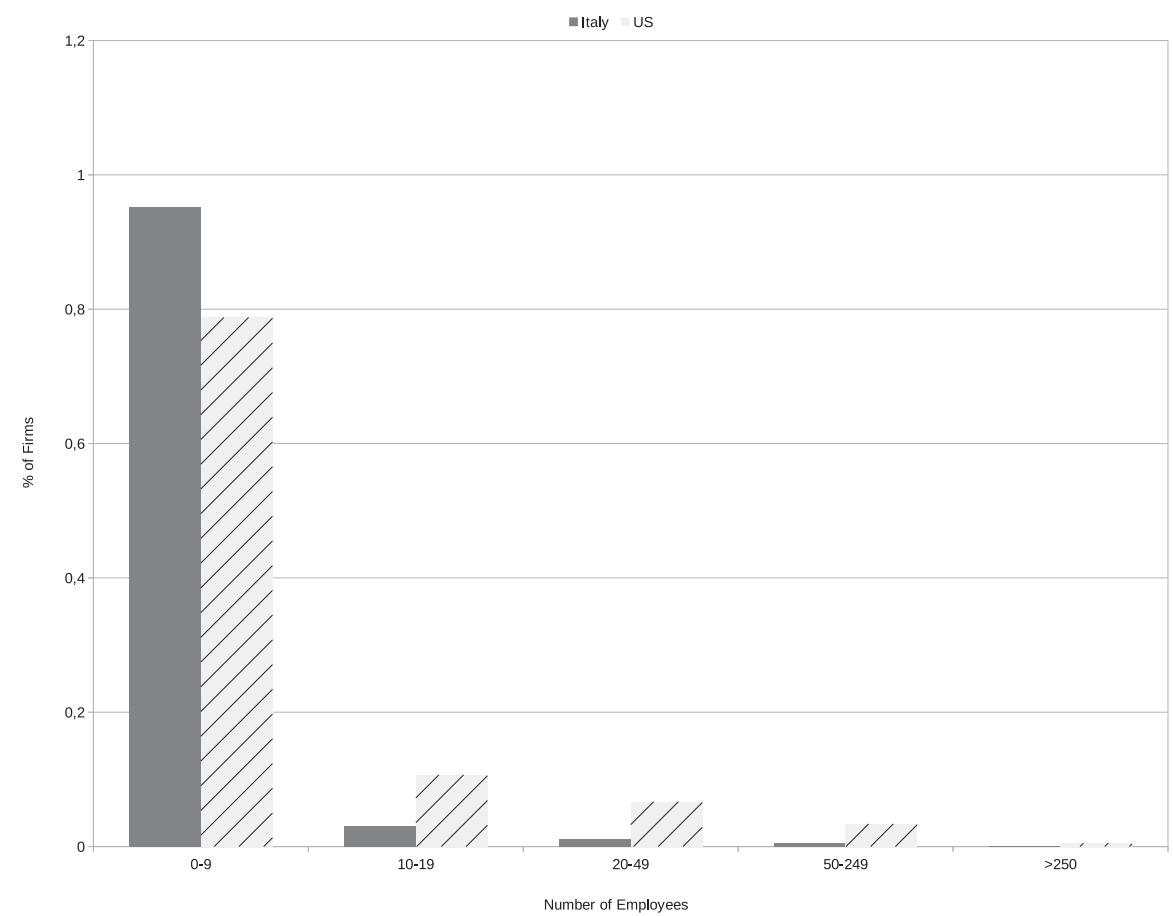

Source: Eurostat and US Census, 2010

\section{Model Economy}

In this section I describe the dynamic general equilibrium heterogeneous agents model I use to conduct a steady state comparison with varying levels of registration and startup costs for businesses. What follows is an outline of its core features and an exposition of the main forces driving the choices faced by the agents in the economy. ${ }^{8}$

The model economy is inhabited by infinitesimal households and a representative firm I will call the corporate sector. Households can choose between managing perfectly competitive businesses, which demand labor and capital and supply the only consumption and investment good in the economy, or supplying their exogenous labor endowments to firms. Households either consume the good, or save endogenously chosen quantities thereof between periods which they supply as capital to businesses and the corporate sector. The corporate sector competes with businesses both by demanding capital and labor, as well as by supplying the consumption good. The corporate sector behaves in a perfectly competitive manner and employs a constant returns to scale technology. ${ }^{9}$

Every period, households randomly receive a business idea they may choose to implement.

\footnotetext{
${ }^{8}$ The model in this paper is based on Gonzalez-Torres (2015), where the reader can find a fully detailed description of the economy, as well as of the solution methods used to solve it. This paper is meant to be self-contained for the non-technical reader.

${ }^{9}$ Given the rich trade-offs households face, they are the centerpiece of the model. The presence of the corporate sector is important in empirical and numerical terms, so as to discipline the policy experiment. The theoretical results of the model would nevertheless remain unchanged in a model without the corporate sector.
} 
Alternatively, they can continue managing a business idea from previous periods. Any time a household starts a business that they were not previously operating, ${ }^{10}$ they face two types of costs: a lump-sum payment in terms of consumption goods $(\Pi)$ and a loss of revenue proportional to their business's productivity $\left(\xi_{R}+\xi_{S}\right)$. Both costs are illustrated in Equation 3.1, the budget constraint faced by entrepreneurs, i.e. households that decide to manage a business. Entrepreneurs consume $\left(c_{i}\right)$, and save $\left(a_{i}^{\prime}-a_{i}\right)$ out of their profits, which are the difference between revenues $\left(\theta_{i}\left(k_{i}^{\alpha} l_{i}^{1-\alpha}\right)^{1-\nu}\right)$ and the sum of capital $\left(r\left(k_{i}-a_{i}\right)+\delta k_{i}\right)$ and labor $\left(w l_{i}\right)$ costs. ${ }^{11}$

$$
c_{i}+\left(a_{i}^{\prime}-a_{i}\right)+\Pi=\left(1-\left(\xi_{R}+\xi_{S}\right)\right) \theta_{i}\left(k_{i}^{\alpha} l_{i}^{1-\alpha}\right)^{1-\nu}-r\left(k_{i}-a_{i}\right)-\delta k_{i}-w l_{i}
$$

The fixed fee $(\Pi)$ entrepreneurs pay when starting a new business does not depend on their productivity $\left(\theta_{i}\right)$, as opposed to the fraction $\left(\xi_{R}+\xi_{S}\right)$ of their revenues they lose. The fixed payment represents the monetary costs entrepreneurs face at the time of registration in Italy and are equal for all entrepreneurs, irrespective of one's current or future productivity. As pointed out in the firm dynamics literature, ${ }^{12}$ a fixed cost of entry into a market deters less productive firms from entering, as their future stream of profits might be too low to compensate for the cost.

On the other hand, the proportional costs in Equation 3.1 represent the fraction of a business's first operating period that an entrepreneur employs in completing the necessary steps to set up a business. Given that this cost is proportional to productivity, more productive businesses will face a higher burden of entry into a market than their less productive counterparts. This creates a negative selection effect on entrepreneurship: high proportional costs, as opposed to fixed costs, deter more productive businesses from entering the market. Additionally, the proportional costs above are separated for empirical reasons: part of the time costs faced by entrepreneurs are due to registration procedures $\left(\xi_{R}\right)$, while the time needed to comply with startup procedures is captured by the second term $\left(\xi_{S}\right)$.

Additionally, entrepreneurs face borrowing constraints in this economy. As illustrated in Equation 3.2, the total amount of resources an entrepreneur owes a bank-principal plus interest - at the end of a period $(1+r)\left(k_{i}-a_{i}\right)$, has to be backed by a fraction $(\phi)$ of the entrepreneur's depreciated capital. ${ }^{13}$

$$
(1+r)\left(k_{i}-a_{i}\right) \leq \phi(1-\delta) k_{i}
$$

\footnotetext{
${ }^{10}$ This includes the case in which a household was previously an entrepreneur, but decides to start a different business.

${ }^{11}$ Notice that households have access to decreasing returns to scale technologies. This assumption, called span of control, is standard in the literature, see Lucas Jr (1978). It implies that a project's size is in equilibrium proportional to its productivity. This way the model delivers a distribution of firm sizes comparable to its empirical counterpart.

${ }^{12}$ Hopenhayn (1992) constitutes a seminal piece of work in this area. The international trade literature, specifically Melitz (2003), first extrapolated the study of the implications of fixed costs for firm dynamics and productivity to other contexts.

${ }^{13}$ This is a standard assumption in the literature, see e.g. Quadrini (2000) or Buera (2009).
} 
Equation 3.2 can be rewritten as Equation 3.3, which will prove to be useful when calibrating the model. It states that entrepreneurs are constrained in the capital-to-asset ratio they can hold for their firms by the financial enforcement parameter $(\phi)$.

$$
\frac{k_{i}}{a_{i}} \leq \frac{1+r}{1+r-\phi(1-\delta)}
$$

All households in the economy are ex-ante equal, i.e. each individual household faces the same choice structure every period as the other agents. Nevertheless, each household's productivity level and occupational choice set is determined idiosyncratically by the shocks they receive individually, their occupational history, and their asset position, as is suggested by explicitly sub-indexing all individual choice variables, as well as households' productivity. In equilibrium, when aggregating across households and the corporate sector, the model structure produces a distribution of household characteristics - asset holdings, occupations and income - as well as a distribution of business characteristics - productivity and size - that can be used to study the distributional and aggregate effects of a policy change in terms of the entry costs entrepreneurs face.

\section{Data and Calibration}

The model used to conduct the policy experiment in this paper is solved using standard numerical methods. ${ }^{14}$ Two sets of parameters need to be assigned values during the solution process. The first set, listed in Table 2, is fixed before solving the model, as their choice is standard across a wide range of models and applications. The second set of parameters, listed in Tables 3 and 4, is calibrated endogenously within the model: I solve the model for a given set of parameters, compare the solution obtained to the relevant data points I collect for Italy, and check whether the solution provides a good fit to the moments found in the data. This process continues until the model reproduces relevant characteristics of the Italian economy.

Table 2: Exogenous parameters

\begin{tabular}{ccc} 
Object & Value & Source \\
\hline \hline Capital Income Share & 0.27 & National Accounts \\
Depreciation & 0.06 & National Accounts \\
Time Registration Cost & 0.04 & WB Doing Business \\
Monetary Registration Cost & 0.8 & WB Doing Business \\
Risk Aversion & 2 & Previous Literature \\
\hline
\end{tabular}

Starting with the exogenously picked parameters, I compute the capital income share and depreciation rate from the Italian national accounts using standard methods in the quantitative literature. I set the coefficient of relative risk aversion for households to a value of 2 , following Hall (2009). I assume that a period in my model corresponds to a natural year. $\xi_{R}$ is corre-

\footnotetext{
${ }^{14}$ See Gonzalez-Torres (2015) for details.
} 
spondingly set to the fraction of a year that registration procedures are measured to take in Italy - 10 business days according to the World Bank Doing Business report. Within the set of exogenously chosen parameters, the World Bank Doing Business Survey provides an exception, as it reports monetary bureaucratic costs as a percentage of income per capita. Consequently, I solve the model for different values of the fixed entry fees within the model, until I find they represent the correct fraction of income per capita within the model.

All the data I use for Italy correspond to the year 2010, including the 2010 SHIW wave and the 2010 Doing Business report. The interest rate is taken from the Bank of Italy's Interest Rate Statistics, which reports the average interest rate on deposits with a pre-established duration, for households and non-financial entities. I compute the average for 2010. Given that the SHIW panel component is small, I obtain data for firm entry and exit by size from the European Statistical Office (Eurostat).

Table 3: Model parameters and corresponding targets Model Object Target

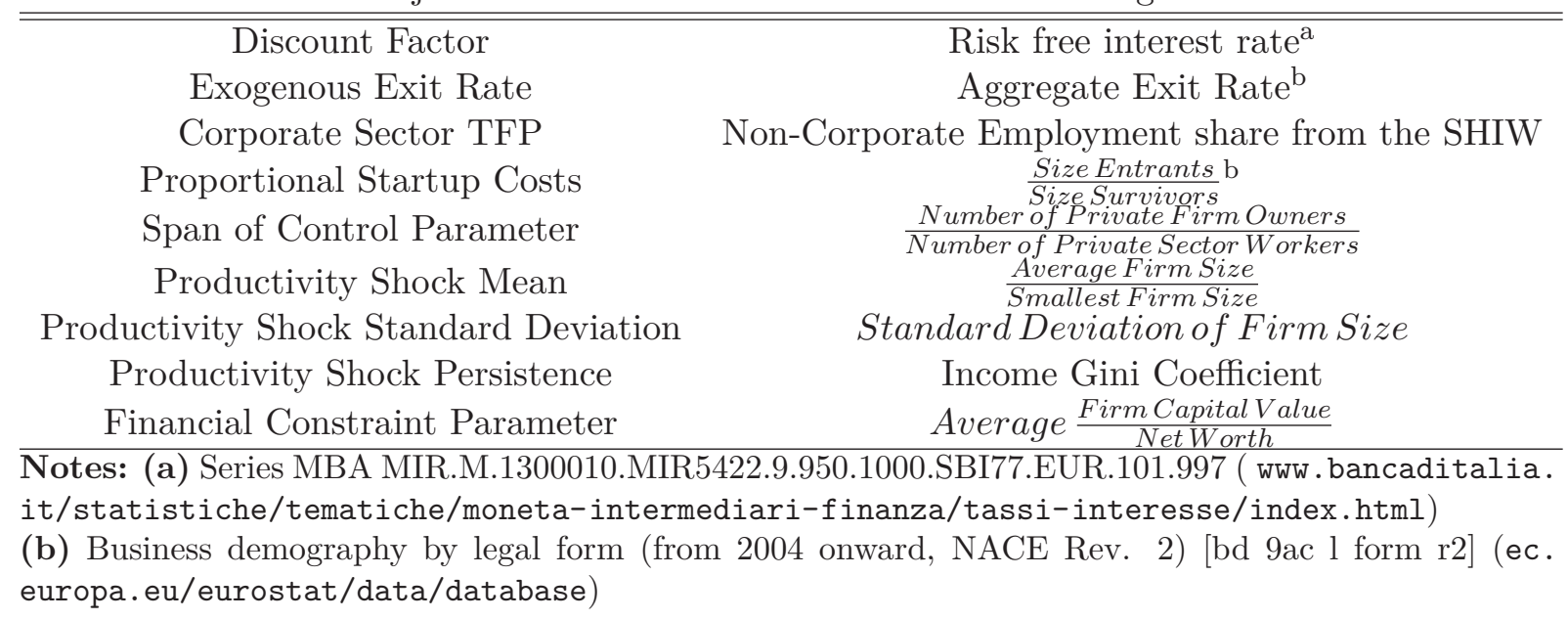

The endogenously calibrated parameters are calibrated jointly, i.e. there is no one-to-one mapping between any given parameter and a certain targeted moment. Nevertheless, certain moments are affected more predominantly by some parameters, which prompts me to design the following calibration strategy: I target the risk-free interest rate $(r)$ described above in order to find a suitable value for the agents' discount factor in the model; I use the exit rate of noncorporate firms to extract information on the exogenous exit rate for businesses in the model; The model assumes that workers not employed by privately held firms are absorbed by an exogenous corporate sector, ${ }^{15}$ hence the employment share of privately held firms contains information on corporate total factor productivity; The level of non-registration related entry costs $\left(\xi_{S}\right)$ is set to approximate the average size of entrants, relative to the average size of survivors, ${ }^{16}$ as higher time entry costs deter firms with higher productivity - therefore also bigger, due to the span

\footnotetext{
${ }^{15}$ This assumption helps discipline the response to a change in entry costs: only the smaller firms with less resources were empirically affected by the OSS reform, as argued in Amici et al. (2015).

${ }^{16}$ This target, or some close alternative to it, is standard in the literature, see for example Clementi and Palazzo (2013)
} 
of control assumption - from entering the market; ${ }^{17}$ I use the ratio of private firm owners to workers in the private sector to extract information on the span of control parameter $(\nu)$ in my economy, given that as entrepreneurs' production functions become less concave, profits increase and more agents will become entrepreneurs as opposed to workers.

As is standard in the literature since Lucas Jr (1978), I use the information contained in the firm size distribution to pin down entrepreneurs' productivity distribution in the model: I use the productivity shock $\left(\theta_{i}\right)$ mean and standard deviation to match the ratios of the average to smallest firm and largest to smallest firm in my data, respectively. ${ }^{18}$ In order to pin down the persistence parameter for the productivity shock, I would ideally use panel data to observe individuals' occupations and income streams. ${ }^{19}$ Given my cross-sectional data, the strategy I adopt is to target the income Gini coefficient among entrepreneurs and workers in the economy: the lower the persistence in the business idea data generating process, the higher the dispersion in the cross-sectional ergodic distribution of business idea shocks in the model economy. This leads to a wider firm size distribution and thus, again due to the span of control assumption, to higher income disparities.

Table 4: Jointly calibrated parameters and corresponding targets

\begin{tabular}{cccc} 
Value & Object & Data & Model \\
\hline \hline 0.98 & Discount Factor & 0.01 & 0.01 \\
0.933 & Exogenous Exit Rate & 0.07 & 0.07 \\
2.3 & Corporate Sector TFP & 0.22 & 0.23 \\
0.3 & Proportional Startup Costs & 0.46 & 0.30 \\
0.355 & Span of Control Parameter & 0.14 & 0.14 \\
0.2 & Productivity Shock Mean & 3.92 & 7.00 \\
0.014 & Productivity Shock Standard Deviation & 5.02 & 3.59 \\
0.882 & Productivity Shock Persistence & 0.26 & 0.10 \\
0.005 & Financial Constraint Parameter & 0.17 & 0.10 \\
\hline
\end{tabular}

Finally, the model includes collateral constraints for entrepreneurs, as illustrated in Equation 3.2. Although the literature has approached this parameter in several ways, most authors have used aggregate data to shed light on it. I use data on privately held firms' financial obligations instead. Following the formulation of the collateral constraints in Equation 3.3, I set the collateral constraint parameter $(\phi)$ to replicate the average capital over net worth ratio that

\footnotetext{
${ }^{17}$ It could be argued that monetary costs could also be split in two - as for example in Gonzalez-Torres (2015). The qualitative results do not vary under either assumption nonetheless. The current choice is motivated by the nature of the policy experiment and the lack of identification including both costs in the model would produce.

${ }^{18}$ Entrepreneurial productivity $\left(\theta_{i}\right)$ is the result of discretizing an $\mathrm{AR}(1)$ process for the logarithm of itself. Tauchen (1986) develops a method to approximate any first-order auto regressive process using a first-order Markov chain, widely used in the literature.

${ }^{19}$ Even though SHIW includes a set of panel households, it is too small to be able to effectively extract estimates from it for my purposes.
} 
I observe in the SHIW: as collateral constraints become tighter for firms, they have a margin to leverage their firms. In the model, as entrepreneurs become more constrained for any given level of asset holdings, they will manage smaller businesses, thus lowering the capital to net worth ratio on average.

An important aspect of the policy experiment conducted here concerns the exact nature of the bureaucratic costs measured by the Doing Business report and the calibration of the startup costs parameter, and, as a corollary, the scope of the experiment's results as well as the policy implications that can be drawn from it. The Doing Business estimates for the time of registering a business cover the bare minimum amount of official procedures an entrepreneur has to complete, ${ }^{20}$ under certain standardizing assumptions regarding the business being registered. ${ }^{21}$ These measures estimate the time costs of the very basic formal requirements dealt with by mostly all businesses registered in an economy. ${ }^{22}$ At the same time, the Doing Business estimates limit, by construction, the depth of the analysis in two important ways. First of all, by considering a standardized firm, the estimates ignore several dimensions along which these bureaucratic entry costs might vary from business to business: varying local or regional authorities, rules and bureaucratic apparatuses; industry specific permits and procedures; or other characteristics such as the number of employees, or the composition of its ownership. The second consideration concerns the fact that bureaucratic costs, be they registration or startup costs, only represent a portion of the costs entrepreneurs face when entering a market. Crucial elements such as information collection, collaborative, financial, supplier, and distribution network building, or even having to overcome informal entry costs all play an important role in firm entry decisions that can be affected by different policies, ${ }^{23}$ but lack data availability, rendering studying them empirically a complicated task.

Therefore, calibrating a startup cost parameter lets the model fill in the costs that entrepreneurs face in real life, but are not measured systematically by indicators like Doing Business. One advantage of my approach is that its policy prescription is, by construction, reasonably clear cut: reduce the time it takes entrepreneurs to enter a certain market to improve the selection of entrepreneurs entering it. In contrast, although I correct for the fact that the Doing Business estimates do not capture all of the entry costs faced by entrepreneurs, my model does not address the fact that the dispersion of the different entry costs entrepreneurs face might affect the selection into different markets. In addition, the calibrated startup cost parameter might capture more than just bureaucratic startup costs, and therefore it will not be clear what portion of the measured effects in my exercise are due to items directly under the control of pol-

\footnotetext{
${ }^{20}$ In terms of startup costs, the Doing Business report includes some measures for the costs of obtaining pertinent construction permits, obtaining access to electricity, and registering property, which I don't include in my calculations.

${ }^{21}$ See http://www.doingbusiness.org/methodology/starting-a-business for further details.

${ }^{22}$ Of course, businesses operating in the informal economy, which might make up a significant proportion of an economy's total activity, do not comply with these procedures. This, however, is outside the scope of the current paper.

${ }^{23}$ See Kayne (1999) for a study of policies on different areas meant to agilize the entry of new firms, and Martínez (2009) for an empirical evaluation of different entrepreneurial-favoring policies in Spain.
} 
icy makers. In synthesis, the present approach provides two insights. First, it gives a prediction on the effects a reduction in entry costs can have on entrepreneurial selection, and aggregate productivity and output. In addition to this, in spite of the discussed data-driven constraints, it also illustrates a theoretical mechanism through which the other factors mentioned above might affect the selection of firms in an economy, or into specific markets. Even though the paper cannot provide direct estimates of the effects that reforming the aforementioned entry barriers might have, it does provide a framework that could assist policy makers and researchers alike in directing future data collection and policy intervention efforts towards those with the highest potential impact on firm selection.

In this sense, the most delicate endogenously calibrated parameter in the model, and at the same time interesting from a policy perspective, is the time cost of starting production other than the registration procedure $\left(\xi_{S}\right)$. Pinpointing an exact number is, as argued, an arduous task. Estimates for Italy could range anywhere from three to eighteen months, depending on the industries and sizes of projects considered, according to De Novellis et al. (2015). Given my model and data, I find a value for $\xi_{S}$ of 0.3 . As a time period in my model corresponds to a year, the estimate would represent about four months. This would fall within the lower estimates of the aforementioned work, as well as significantly above the 10 days registration procedures were estimated to last in Italy by Doing Business at that time.

The estimate obtained for the length of the startup process could have important implications, given that it is significantly longer and its procedures are more elaborate than those of the registration process in Italy. Attention to the design of future policies, as well as to research, should be shifted from registration costs - which have traditionally been taken as a proxy for all entry costs - to all the procedures that conform the startup process for firms. A very notable effort to document and quantify the process should be encouraged, in order to make comparisons across different legal frameworks possible and to guide policy makers and legislative bodies in their efforts to lower bureaucratic hurdles for businesses.

\section{$5 \quad$ Policy Experiment}

The policy experiment in this paper is conducted as follows: having calibrated the model economy to replicate relevant features of the Italian economy, I first cut registration time $\left(\xi_{R}\right)$ from 10 to 6 days, as measured by Doing Business after the introduction of the Comunicazione Unica. Next, I lower the proportional startup costs faced by entrepreneurs in the model $\left(\xi_{S}\right)$, again by $40 \%$. I measure the effects both scenarios have on aggregate output and productivity, entrepreneurial selection, as well as on consumption and income inequality and compare the results of each intervention.

Table 5 summarizes the results of the policy experiments described above. All the results are presented in percentages of the original state values. Total factor productivity is measured in a growth accounting manner, i.e. by adding up the output of all firms as well as all the productive factors used to produce, assuming a constant returns to scale production function for the entire 
economy, and backing out total factor productivity as if produced by a single representative firm. The unconditional average productivity of entrepreneurs captures entrepreneurial selection through privately held firms' productivity. ${ }^{24}$ Size-weighted average entrepreneur productivity, in comparison to unconditional average productivity, captures the extent to which the entry of new businesses distorts the allocation of productive resources. ${ }^{25}$ The percentage of labor hired in the corporate sector represents those workers offering their services to firms large enough, and with enough resources, that the bureaucratic hurdles $\left(\xi_{R}\right)$ and $\left(\xi_{S}\right)$ would not affect them. All other entries in Table 5 should be self-explanatory.

Table 5: Percentage deviation from benchmark

Lower Lower

\begin{tabular}{ccc} 
& Registration Time & Startup Time \\
\hline \hline GDP per capita : & +0.03 & +1.91 \\
TFP : & +0.05 & +4.30 \\
Unc. Avg Productivity : & +0.01 & +0.82 \\
Size-wtd Avg Productivity : & +0.02 & +1.01 \\
Size Entrants/Survivors : & +1.44 & +8.43 \\
\% Labor in Corp. Sector : & -1.18 & -10.3 \\
Income Gini Coefficient : & +0.24 & +9.20 \\
Wealth Gini Coefficient : & -0.16 & -3.43 \\
\hline
\end{tabular}

The first result that becomes clear from Table 5 is that reducing the time it takes to both register a business and then obtain all necessary permits to start operating has positive effects on both aggregate productivity and output. These observations are in line with what the previous literature has found, including Amici et al. (2015) for the case of the OSS reform in Italy. By construction of the model, both parameters have equal qualitative results, but given the estimates for each, the quantitative results differ. In this exercise, reducing the time it takes to register a business has an effect an order of magnitude smaller than lowering the procedural times of the startup process. This is mainly due to the relative size of each type of cost in the baseline model.

In terms of entrepreneurial selection, the model predicts positive effects both on the average productivity of small entrepreneurs, as well as on the size-weighted productivity of entrepreneurs. Again, this is in line with previous research on the OSS reform. On the other hand, looking at the relative size of entrants and survivors, a reduction in the time it takes to go through all the necessary bureaucracy attracts larger entrants - thus pointing towards a better selection of entrepreneurs. In addition, the overall size of the non-corporate sector, i.e. the firms affected by entry costs in the model, increases under both policy interventions, pointing towards an increased entry of firms.

The final set of results in Table 5 concerns the distribution of households in the economy. Lower entry costs into entrepreneurship increase income inequality, both because already previ-

\footnotetext{
${ }^{24}$ It is simply measured in the model as the average of all $\theta_{i}$ of firms in the market.

${ }^{25}$ I use the size in terms of employees to weight each firm's $\theta_{i}$ in the model.
} 
ously operating entrepreneurs might decide to upgrade their technologies under the lower entry costs, as well as due to an increase in the number of entrepreneurs, whose incomes increase with respect to workers. On the other hand, wealth inequality falls in the economy after the policy intervention. This effect works mainly through the financial constraints entrepreneurs face: with lower entry costs, potential entrepreneurs need to save less, in case they decide to enter the market, thus lowering wealth inequality in the model. ${ }^{26}$

\section{Concluding Remarks}

Bureaucratic hurdles to firm creation have historically been surprisingly high even among various OECD countries. Reducing these has been a policy priority in recent years across different countries, including Italy. I study the aggregate and firm-level effects that a reduction in the time spent registering a new firm and subsequently complying with different startup requisites could have in the long run. Previous work has examined this and other similar reforms in microoriented frameworks, with results pointing in the same direction as the ones I obtain: the longer it takes entrepreneurs to start their businesses, the lower the incentive is for potentially more productive firms to enter the market. Additionally, I find the time required to comply with startup procedures might be significantly longer than the length of the registration procedure in Italy - undoubtedly better documented and quantified than the former - thus rendering the effects of reforming the startup process orders of magnitude greater than the effects any further shortening of registration times could have.

Two main lessons are derived from this literature: first, that any non-essential, time-consuming legal requirements should be reduced to a bare minimum, as the gains in terms of firm selection, productivity, and output might be significant. Even though the literature is agnostic about the positive role registration and startup procedures might have, an alternative to these could be an increase in entry fees, ${ }^{27}$ bearing positive selection properties, that might finance an alternative screening scheme, should it be of economic value.

Second, as the availability of richer data is rare, this literature looks at bureaucratic hurdles only, furthermore without attention to local-, industry-, or size-specific variation. Issues like legal heterogeneity, market structure, networking opportunities, or political economy considerations may add to the time it takes for entrepreneurs to establish their businesses. Analogously to bureaucratic procedures, any element involving entrepreneurs in time-costly actions, could have sizable negative effects on entrepreneurial selection and the aggregate economy. It therefore seems crucial, that an effort be made to provide both researchers and policy makers with data to understand what other time-saving policy interventions could be beneficial to economies.

\footnotetext{
${ }^{26}$ See Quadrini (2000) or Cagetti and De Nardi (2006) for classic references on the relationship between wealth inequality and entrepreneurship.

${ }^{27}$ In the presence of financial constraints, increased entry fees might produce a misallocation of productive resources by impeding agents with productive ideas but few assets from operating at their optimal scales. This further complicates finding the right balance between entry fees and the length of entry procedures, which I find crucial be further explored in future research. I thank Luigi Federico Signorini for pointing this out.
} 


\section{References}

Monica Amici, Silvia Giacomelli, Francesco Manaresi, and Marco Tonello. Red tape reduction and firm entry: evidence from an italian reform. Questioni di Economia e Finanza (Occasional Papers) 285, Bank of Italy, Economic Research and International Relations Area, July 2015.

L. Barseghyan. Entry costs and cross-country differences in productivity and output. Journal of Economic Growth, 13(2):145-167, 2008.

L. Barseghyan and R. DiCecio. Entry costs, industry structure, and cross-country income and tfp differences. FRB of St. Louis Working Paper No. 2009-005D, 2010.

Miriam Bruhn. License to sell: the effect of business registration reform on entrepreneurial activity in mexico. The Review of Economics and Statistics, 93(1):382-386, 2011.

F.J. Buera. A dynamic model of entrepreneurship with borrowing constraints: theory and evidence. Annals of finance, 5(3):443-464, 2009.

M. Cagetti and M. De Nardi. Entrepreneurship, frictions, and wealth. Journal of Political Economy, 114(5):835-870, 2006.

Gian Luca Clementi and Berardino Palazzo. Entry, exit, firm dynamics, and aggregate fluctuations. Working paper, National Bureau of Economic Research, 2013.

F. De Novellis, G. Della Rocca, C. Peiti, and S. Signorini. Iter autorizzativi e semplificazione: la conferenza di servizi. Technical report, Confindustria Toscana Sud, 2015.

S. Djankov, R. La Porta, F. Lopez-de Silanes, and A. Shleifer. The regulation of entry. The Quarterly Journal of Economics, 117(1):1, 2002.

Simeon Djankov. The regulation of entry: A survey. The World Bank Research Observer, page lkp005, 2009.

Guzman Gonzalez-Torres. Essays on the Macroeconomic Effects of Inequality. PhD thesis, Stanford University, Stanford CA, 2015. Chapter I: Aggregate Effects of Bureaucratic Startup Costs.

Robert E Hall. Reconciling cyclical movements in the marginal value of time and the marginal product of labor. Journal of political Economy, 117(2):281-323, 2009.

H.A. Hopenhayn. Entry, exit, and firm dynamics in long run equilibrium. Econometrica: Journal of the Econometric Society, pages 1127-1150, 1992.

Jay Kayne. State entrepreneurship policies and programs. Available at SSRN 1260444, 1999.

L. Klapper, L. Laeven, and R. Rajan. Entry regulation as a barrier to entrepreneurship. Journal of Financial Economics, 82(3):591-629, 2006. 
R.E. Lucas Jr. On the size distribution of business firms. The Bell Journal of Economics, pages 508-523, 1978.

José A Belso Martínez. Entrepreneurship policies and new business performance and growth: an empirical analysis based on manufacturing industries. Environment and Planning C: Government and Policy, 27(2):195-215, 2009.

Marc J Melitz. The impact of trade on intra-industry reallocations and aggregate industry productivity. Econometrica, 71(6):1695-1725, 2003.

Thomas Philippon and Nicolas Véron. Financing europe's fast movers. Policy brief, Bruegel, January 2008.

V. Quadrini. Entrepreneurship, saving, and social mobility. Review of Economic Dynamics, 3 (1):1-40, 2000.

Enrique Seira, David S Kaplan, and Eduardo Piedra. Entry regulation and business start-ups: Evidence from mexico. Available at SSRN 978863, 2007.

George Tauchen. Finite state markov-chain approximations to univariate and vector autoregressions. Economics letters, 20(2):177-181, 1986. 